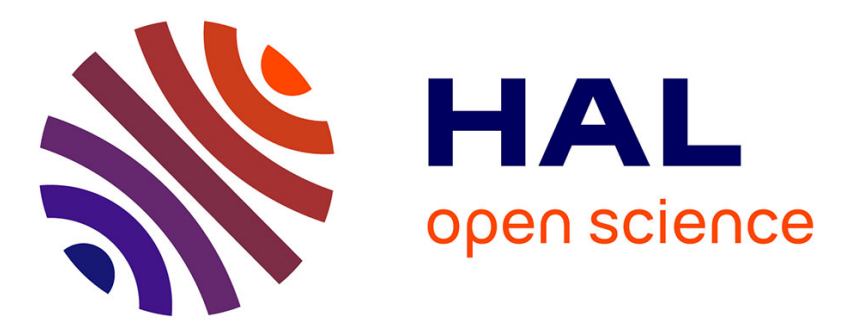

\title{
Ascoma genotyping and mating type analyses of mycorrhizas and soil mycelia of Tuber borchii in a truffle orchard established by mycelial inoculated plants
} Pamela Leonardi, Claude Murat-Furminieux, Federico Puliga, Mirco Iotti, Alessandra Zambonelli

\section{To cite this version:}

Pamela Leonardi, Claude Murat-Furminieux, Federico Puliga, Mirco Iotti, Alessandra Zambonelli. Ascoma genotyping and mating type analyses of mycorrhizas and soil mycelia of Tuber borchii in a truffle orchard established by mycelial inoculated plants. Environmental Microbiology, 2019, 10.1111/14622920.14777 . hal-02352497

\section{HAL Id: hal-02352497 \\ https://hal.science/hal-02352497}

Submitted on 6 Nov 2019

HAL is a multi-disciplinary open access archive for the deposit and dissemination of scientific research documents, whether they are published or not. The documents may come from teaching and research institutions in France or abroad, or from public or private research centers.
L'archive ouverte pluridisciplinaire HAL, est destinée au dépôt et à la diffusion de documents scientifiques de niveau recherche, publiés ou non, émanant des établissements d'enseignement et de recherche français ou étrangers, des laboratoires publics ou privés.

\section{다(1)(2)}

Distributed under a Creative Commons Attribution - ShareAlikel 4.0 International 


\section{Ascoma genotyping and mating type analyses of mycorrhizas and soil mycelia of Tuber borchii in a truffle orchard established by mycelial inoculated plants}

\author{
Pamela Leonardi, ${ }^{1}$ Claude Murat, ${ }^{2}$ Federico Puliga, ${ }^{1}$ \\ Mirco lotti ${ }^{3}$ and Alessandra Zambonelli (i) ${ }^{1 *}$ \\ ${ }^{1}$ Department of Agricultural and Food Sciences, \\ University of Bologna, viale Fanin 44, 40127, Bologna, \\ Italy. \\ ${ }^{2}$ Université de Lorraine, INRA, UMR IAM, 54000, Nancy, \\ France. \\ ${ }^{3}$ Department of Life, Health and Environmental Science, \\ University of L'Aquila, via Vetoio, 67100, Coppito, \\ L'Aquila, Italy.
}

\section{Summary}

Tuber borchii (the Bianchetto truffle) is a heterothallic Ascomycete living in symbiotic association with trees and shrubs. Maternal and paternal genotype dynamics have already been studied for the black truffles Tuber melanosporum and Tuber aestivum but not yet for T. borchii. In this study, we analysed maternal and paternal genotypes in the first truffle orchard realized with plants inoculated with five different $T$. borchii mycelia. Our aims were to test the persistence of the inoculated mycelia, if maternal and/or paternal genotypes correspond to inoculated mycelia and to assess the hermaphroditism of $T$. borchii. The mating type of each isolate as well as those of mycorrhizas, ascomata and extraradical soil mycelia was determined. Moreover, simple sequence repeat (SSR) profiles of maternal and paternal genotypes were assessed in 18 fruiting bodies to investigate the sexual behaviour of this truffle. The maternal genotypes of the fruiting bodies corresponded to those of the inoculated mycelia with only two exceptions. This confirmed that the inoculated mycelia persisted 9 years after plantation. As regards paternal partner, only two had the same genotype as those of the inoculated mycelia, suggesting hermaphroditism. Most of the new paternal genotypes originated from a recombination of those of inoculated mycelia.

Received 12 April, 2019; revised 29 July, 2019; accepted 5 August, 2019. *For correspondence. E-mail alessandr.zambonelli@unibo.it; Tel. +39 0512096579; Fax +390512096241.
Introduction

Ectomycorrhizal fungi assist plants in their growth, therefore, playing key roles in forest ecosystem functioning. In addition, some of them produce edible fructifications representing income opportunities for farmers and foresters. True truffles are hypogeous fungi belonging to the genus Tuber, which live in ectomycorrhizal association with a wide range of shrubs and trees (Zambonelli et al., 2016). The genus Tuber comprises around 200 species but only a few of them have a considerable value, such as the European species Tuber magnatum Picco (Italian white truffle), Tuber melanosporum Vittad. (black truffle), Tuber aestivum Vittad. (summer truffle) and Tuber borchii Vittad. (bianchetto truffle) (Bonito et al., 2010). In recent years, important milestones have been reached, allowing a better understanding of the truffle life cycle. In 2006, Paolocci and colleagues found that T. magnatum is heterothallic and its ectomycorrhizas are formed by primary (homokaryotic) mycelia. This condition was also confirmed in T. melanosporum (Riccioni et al., 2008; Rubini et al., 2011a) and T. borchii (Belfiori et al., 2016), indicating that heterothallic life style is common within the Tuber genus and fruiting body production depends on the mating between mycelia harbouring different mating types. Mycelia of both mating types can act as a maternal partner, indicating hermaphroditism (Selosse et al., 2017). The haploid maternal genotype of truffles forms the sterile tissues of the fruiting body, and it is fed from the surrounding mycorhizas throughout the maturation time (Rubini et al., 2011a; Le Tacon et al., 2013; Murat et al., 2013). On the contrary, the paternal genes are confined to the asci and, indeed, the paternal genotypes were rarely found to form mycorrhizas (Taschen et al., 2016; De la Varga et al., 2017).

In addition to the characterization of mating type idiomorphs, the sequencing of the $T$. melanosporum genome (Martin et al., 2010) has allowed large-scale screening of SSR markers, which are being implemented on a small scale in field trials in order to unravel the interaction between maternal and paternal genotypes. In the field, T. melanosporum displays a strong genetic isolation with strains of opposite mating types spatially confined in separate patches in which a few dominant genotypes can persist throughout the years (Rubini et al., 2011b; Taschen et al., 
2016; De la Varga et al., 2017). Due to the important turnover and small spatial size of the paternal genotypes, it has been suggested that in most cases germinating ascospores could act as a paternal partner (Selosse et al., 2013; Le Tacon et al., 2016; Taschen et al., 2016; De la Varga et al., 2017; Selosse et al., 2017). However, this hypothesis remains to be demonstrated, and the nature of the paternal genotype is still unclear.

Tuber borchii was long used as a model species within the Tuber genus for transcriptomic and functional analyses. Tuber borchii, together with $T$. aestivum, is the species with the widest diffusion in Europe, adapting to different climatic and soil conditions (Zambonelli et al., 2002; Gardin, 2005; Hall et al., 2007; Lancellotti et al., 2016). For its gastronomic value and adaptability to different environmental conditions, $T$. borchii cultivation was introduced in European Mediterranean countries (Italy, Portugal and Spain) and in non-European countries (Zambonelli et al., 2015; Hall et al., 2017). The cultivation of T. borchii, similarly to that of other truffles, is achieved by synthetizing mycorrhizal plants in specialized nurseries by spore inoculum and planting them in suitable places (Chevalier and Grente, 1978; Hall et al., 2007). Mycelial inoculum was successfully tested in the second half of the last century to obtain Tuber mycorrhizal plants (Palenzona et al., 1972; Chevalier, 1973) but, later, it was applied only for experimental purposes due to the difficulties of obtaining large quantities of mycelium for largescale inoculation purposes (lotti et al., 2002; Giomaro et al., 2005; lotti et al., 2012a). Also, once reliable methods for growing $T$. borchii mycelium had been perfected, mycelial inoculation was no longer used because it was commonly thought that the obtained plants would not have been able to produce fruiting bodies due to heterothallic sexual reproduction of truffles (Zambonelli et al., 2008).

Recently, the first truffle orchard realized with plants inoculated by $T$. borchii mycelia began to produce (lotti et al., 2016). This truffle orchard was established in Cadriano (Bologna) inside an intensive agricultural area where $T$. borchii had not been found for at least 30 years (Zambonelli and Morara, 1984; Morara et al., 2009). Moreover, the presence of large mycophagus mammals like wild boars, which could introduce truffle spores in the orchard from far sites (Piattoni et al., 2014), was excluded. The plants were inoculated with five different strains singly and in mixture. Truffle production was first assessed in February 2016, 9 years after planting. We hypothesized that the strains used for inoculation had different mating types and that fertilization had occurred between them (lotti et al., 2016). This plantation represents a unique opportunity to investigate $T$. borchii sexual reproduction.

The aims of this study were to address the following questions (i) were mycelium genotypes able to be perennial for 9 years in the root system? (ii) did maternal genotypes correspond to mycelium used for plant inoculation? (iii) did paternal genotypes correspond to offspring of original genotypes or was hermaphroditism more frequent in $T$. borchii than T. melanosporum? In order to address these questions, polymorphic simple sequence repeat (SSR) markers were identified in the T. borchii genome (Murat et al., 2018). These SSRs were applied to genotype the inoculated strains used for plant colonization, as well as maternal and paternal genotypes of harvested ascomata. Mating type distribution in the orchard was also determined for inoculated mycelia, mycorrhizas, ascomata and soil samples.

\section{Results}

\section{SSR characterization}

More than 1000 SSRs (1111 in total) were found in the $T$. borchii genome. Among the 31 SSR primer pairs selected in silico analysis, 14 were used in subsequent analyses since produced a single band per sample and showed polymorphisms. They were used to analyse the polymorphism of 50 ascomata harvested in Italy and Hungary as well as the samples from the Cadriano truffle orchard. MLGsim analysis showed that all the 50 ascomata from Italy and Hungary were different from each other, resulting in 50 multilocus genotypes (MLGs) (genotypic diversity = 1; Supporting Information Table S1). The number of alleles ranged from 3 to 10 and the He from 0.208 to 0.739 (Table 1 and Supporting Information Table S1). Most of the SSRs are localized in intergenic regions with the exception of Tb151, Tb293 and Tb46 that are localized in gene models.

\section{Genotyping of the inoculated mycelia}

The SSRs and mating type analyses made it possible to genotype the five $T$. borchii strains used to inoculate

Table 1. Characteristics of the 14 SSRs used to characterize the Tuber borchii clones involved in this study.

\begin{tabular}{lllrl}
\hline $\begin{array}{l}\text { SSR } \\
\text { name }\end{array}$ & \multicolumn{1}{c}{$\begin{array}{c}\text { Repeat } \\
\text { motif }\end{array}$} & $\begin{array}{c}\text { Genome } \\
\text { localization }^{\mathrm{a}}\end{array}$ & $\mathrm{Na}^{\mathrm{b}}$ & $\mathrm{He}^{\mathrm{c}}$ \\
\hline Tb244 & $(\mathrm{GAGGGA})_{6}$ & $\begin{array}{l}\text { Intergenic } \\
\text { Intergenic }\end{array}$ & 5 & 0.562 \\
Tb1 & $(\mathrm{TATTTT})_{10}$ & 3 & 0.626 \\
Tb83 & $(\mathrm{GACT})_{8}$ & Intergenic & 3 & 0.263 \\
Tb11 & $(\mathrm{AGGC})_{8}$ & Intergenic & 4 & 0.319 \\
Tb151 & $(\mathrm{AAC})_{8}$ & Gene model (UTR) & 8 & 0.472 \\
Tb155 & $(\mathrm{GGA})_{12}$ & Intergenic & 7 & 0.649 \\
Tb156 & $(\mathrm{GAG})_{8}$ & Intergenic & 5 & 0.432 \\
Tb17 & $(\text { TTTAGA })_{5}$ & Intergenic & 3 & 0.266 \\
Tb206 & $(\mathrm{CCTT})_{8}$ & Intergenic & 3 & 0.617 \\
Tb293 & $(\text { AGAAGG })_{5}$ & Gene model (intron) & 10 & 0.739 \\
Tb43 & $(\mathrm{CTTTT})_{5}$ & Intergenic & 4 & 0.255 \\
Tb704 & $(\mathrm{AAAG})_{8}$ & Intergenic & 6 & 0.595 \\
Tb43bis & $(\mathrm{TACC})_{8}$ & Intergenic & 4 & 0.208 \\
Tb46 & $(\text { AGA })_{9}$ & Gene model (CDS) & 6 & 0.456 \\
\hline
\end{tabular}

a. UTR = untranslated region, $\mathrm{CDS}=$ coding sequence.

b. $\mathrm{Na}=$ number of allele observed

c. $\mathrm{He}=$ expected heterozygosity. 
truffle seedlings. The strain 2364 was assigned to CMLG_13, the strain Tb98 to C-MLG_8, the strain 1Bo to C-MLG_6, the strain 2292 to C-MLG_18 and the strain 2352 to the C-MLG_14. Two strains (2292 and 1Bo) have the MAT 1-2-1 gene coding for the HMG-domain protein and the other three strains (Tb98, 2352 and 2364) have the MAT 1-1-1 gene coding for the alpha-domain protein (Table 2). Although the arrangement of the groups of plants inoculated with the same strain(s) in four rows along the plantation was casual at the time of plantation, the distribution of the two mating types proved to be spatially alternated across the truffle ground (Fig. 1).

\section{Genotyping of the maternal tissue (gleba) and mating characterization of ECM and soil mycelium}

The maternal tissue of 18 ascomata out of 33 collected in the truffle orchard was successfully genotyped using both SSR and mating type primers (Tables 2 and 3). At least two ascomata for each plant group inoculated with the same strain were genotyped. The other 15 ascomata were only mating typed and not considered for SSR analyses because the respective paternal genotypes failed to be characterized (Table 2).

Amplifications of the maternal tissue with both mating type and SSR primers gave single and specific amplicons. The 18 ascomata were grouped into 6 different genotypes (CMLGs): 4 with MAT 1-1-1 (C-MLG_8, C-MLG_13, CMLG_10 and C-MLG_14) and 2 with MAT 1-2-1 (C-MLG_3 and C-MLG_18) (Table 2 and Supporting Information Table S2). Most of the analysed ascomata (15/18) have the same C-MLG of the strains used to inoculate the plants where they were collected (C-MLG_8, C-MLG_13, CMLG_18 and C-MLG_14). Three female genotypes (CMLG_8, C-MLG_13 and C-MLG_14) showed a significant P sex value that supports the hypothesis that the ascomata of each of these genotypes are a part of the same clone (Supporting Information Table S3). One ascoma (4658), found in the group of plants inoculated with the strain 1Bo (C-MLG_6) had the same genotype (C-MLG_14) of the

Table 2. Genotyping of the inoculated strain and of the ascoma, ectomycorrhizas, and mycelium at the points where the samples were collected.

\begin{tabular}{|c|c|c|c|c|c|c|c|c|c|}
\hline \multirow{2}{*}{$\begin{array}{l}\text { Plant } \\
\mathrm{n} .\end{array}$} & \multirow{2}{*}{$\begin{array}{c}\text { Sample } \\
n\end{array}$} & \multirow{2}{*}{$\begin{array}{c}\text { Inoculated strain } \\
n\end{array}$} & \multicolumn{4}{|c|}{ Mating type ${ }^{a}$} & \multirow[b]{2}{*}{ Strain genotype } & \multicolumn{2}{|c|}{ Ascoma genotypes } \\
\hline & & & Strain & Ascoma & $\mathrm{ECM}$ & Soil & & Maternal & Paternal \\
\hline 1 & 4597 & 2292 & 2 & 2 & 2 & 2 & C-MLG_18 & nd & nd \\
\hline 46 & 4598 & $\mathrm{~Tb} 98$ & 1 & 1 & nd & nd & C-MLG_8 & C-MLG_8 & C-MLG_7 \\
\hline 10 & 4599 & $\mathrm{~Tb} 98$ & 1 & 1 & nd & nd & C-MLG_8 & C-MLG_8 & C-MLG_2 \\
\hline 69 & 4600 & 2364 & 1 & 1 & nd & nd & C-MLG_13 & C-MLG_13 & C-MLG_1 \\
\hline 63 & 4601 & $1 \mathrm{Bo} \leftarrow$ & 2 & 2 & nd & nd & C-MLG_6 & C-MLG_3 & C-MLG_14 \\
\hline 47 & 4602 & Tb 98 & 1 & 1 & nd & nd & C-MLG_8 & C-MLG_8 & C-MLG_18 \\
\hline 33 & 4633 & $2364 \leftarrow$ & 1 & 1 & 1 & 1 & C-MLG_13 & C-MLG_10 & C-MLG_20 \\
\hline 39 & 4634 & 2292 & 2 & 2 & nd & nd & C-MLG_18 & C-MLG_18 & C-MLG_5 \\
\hline 68 & 4635 & 2364 & 1 & 1 & nd & nd & C-MLG_13 & C-MLG_13 & C-MLG_16 \\
\hline 15 & 4639 & MIX & na & 2 & 2 & 2 & na & nd & nd \\
\hline 51 & 4640 & MIX & na & 1 & 1 & 1 & na & nd & nd \\
\hline 44 & 4641 & Tb 98 & 1 & 1 & 1 & 1 & C-MLG_8 & nd & nd \\
\hline 65 & 4642 & 1Bo & 2 & 2 & 2 & 1 & C-MLG_6 & nd & nd \\
\hline 6 & 4644 & Tb 98 & 1 & 1 & 1 & 1 & C-MLG_8 & nd & nd \\
\hline 47 & 4647 & $\mathrm{~Tb} 98$ & 1 & 1 & 1 & 1 & C-MLG_8 & nd & nd \\
\hline 10 & 4648 & Tb 98 & 1 & 1 & nd & nd & C-MLG_8 & C-MLG_8 & C-MLG_15 \\
\hline 44 & 4649 & Tb 98 & 1 & 1 & nd & nd & C-MLG_8 & C-MLG_8 & C-MLG_19 \\
\hline 23 & 4650 & 2352 & 1 & 1 & 1 & 1 & C-MLG_14 & nd & nd \\
\hline 59 & 4651 & 2352 & 1 & 1 & 1 & 1 & C-MLG_14 & C-MLG_14 & C-MLG_4 \\
\hline 61 & 4652 & 2352 & 1 & 1 & 1 & 1 & C-MLG_14 & C-MLG_14 & C-MLG_2 \\
\hline 68 & 4653 & 2364 & 1 & 1 & 1 & 1 & C-MLG_13 & C-MLG_13 & C-MLG_9 \\
\hline 45 & 4654 & TB98 & 1 & 1 & 1 & 1 & C-MLG_8 & nd & nd \\
\hline 41 & 4655 & 2292 & 2 & 2 & 2 & 2 & C-MLG_18 & nd & nd \\
\hline 44 & 4656 & TB98 & 1 & 1 & 1 & 1 & C-MLG_8 & C-MLG_8 & C-MLG_7 \\
\hline 52 & 4657 & MIX & na & 1 & 1 & 1 & na & C-MLG_14 & C-MLG_17 \\
\hline 65 & 4658 & $1 \mathrm{Bo} \leftarrow$ & 2 & 1 & nd & nd & C-MLG_6 & C-MLG_14 & C-MLG_11 \\
\hline 6 & 4659 & TB98 & 1 & 1 & 1 & 1 & C-MLG_8 & nd & nd \\
\hline 17 & 4660 & MIX & na & 2 & 2 & 2 & na & nd & nd \\
\hline 27 & 4662 & 2352 & 1 & 1 & 1 & 1 & C-MLG_14 & nd & nd \\
\hline 52 & 4664 & MIX & na & 1 & 1 & 1 & na & C-MLG_8 & C-MLG_21 \\
\hline 13 & 4675 & MIX & na & 1 & 1 & 1 & na & C-MLG_8 & C-MLG_12 \\
\hline 65 & 4677 & 1Bo & 2 & 2 & 2 & 1 & C-MLG_6 & nd & nd \\
\hline 13 & 4699 & MIX & na & 1 & 1 & 1 & na & nd & nd \\
\hline
\end{tabular}

The arrows indicate the samples having a maternal C-MLG (in bold) different from the inoculated strain. nd = not determined. na $=$ not applicable. a. 1 correspond to the mating type MAT 1-1-1; 2 correspond to MAT 1-2-1.

b. C-MLG of the strain 2352 . 
Table 3. Metadata of the T. borchii ascomata of Cadriano truffle ground used in this study.

\begin{tabular}{|c|c|c|c|c|c|}
\hline Ascoma & Sampling date & Weight (g) & Plant & Tree species & Inoculated strain \\
\hline 4597 & 08/02/2016 & 35 & 1 & Pinus pinea & 2292 \\
\hline 4598 & 08/02/2016 & 34 & 46 & Pinus pinea & Tb98 \\
\hline 4599 & 08/02/2016 & 13.9 & 10 & Quercus pubescens & Tb98 \\
\hline 4600 & 08/02/2016 & 54.7 & 69 & Corylus avellana & 2364 \\
\hline 4601 & 08/02/2016 & 20.9 & 63 & Quercus pubescens & 1Bo \\
\hline 4602 & 08/02/2016 & 2 & 47 & Pinus pinea & Tb98 \\
\hline 4633 & 12/02/2016 & 0.59 & 33 & Quercus robur & 2364 \\
\hline 4634 & $12 / 02 / 2016$ & 1 & 39 & Quercus pubescens & 2292 \\
\hline 4635 & $12 / 02 / 2016$ & 2.28 & 68 & Quercus robur & 2364 \\
\hline 4639 & 19/02/2016 & 5.53 & 15 & Pinus pinea & MIX \\
\hline 4640 & $19 / 02 / 2016$ & 9.73 & 51 & Quercus pubescens & MIX \\
\hline 4641 & 19/02/2016 & 6.84 & 44 & Quercus pubescens & Tb98 \\
\hline 4642 & 19/02/2016 & 3.42 & 65 & Pinus pinea & $1 \mathrm{BO}$ \\
\hline 4644 & 19/02/2016 & 0.27 & 6 & Quercus pubescens & TB98 \\
\hline 4647 & 19/02/2016 & 27.73 & 47 & Pinus pinea & TB98 \\
\hline 4648 & $25 / 02 / 2016$ & 9.94 & 10 & Quercus pubescens & Tb98 \\
\hline 4649 & 25/02/2016 & 0.53 & 44 & Quercus pubescens & Tb98 \\
\hline 4650 & $25 / 02 / 2016$ & 6.18 & 23 & Pinus pinea & 2352 \\
\hline 4651 & 25/02/2016 & 0.38 & 59 & Pinus pinea & 2352 \\
\hline 4652 & $25 / 02 / 2016$ & 17.23 & 61 & Pinus pinea & 2352 \\
\hline 4653 & $25 / 02 / 2016$ & 7.39 & 68 & Quercus robur & 2364 \\
\hline 4654 & 25/02/2016 & 2.73 & 45 & Quercus pubescens & TB98 \\
\hline 4655 & 25/02/2016 & 5.17 & 41 & Quercus pubescens & 2292 \\
\hline 4656 & 25/02/2016 & 1.19 & 44 & Quercus pubescens & Tb98 \\
\hline 4657 & 25/02/2016 & 12.79 & 52 & Quercus pubescens & MIX \\
\hline 4658 & 25/02/2016 & 6.66 & 65 & Pinus pinea & 1Bo \\
\hline 4659 & 02/03/2016 & 4.67 & 6 & Quercus pubescens & Tb98 \\
\hline 4660 & 02/03/2016 & 6.33 & 17 & Pinus pinea & MIX \\
\hline 4662 & 02/03/2016 & 19.24 & 27 & Quercus pubescens & 2352 \\
\hline 4664 & 02/03/2016 & 6.96 & 52 & Quercus pubescens & MIX \\
\hline 4675 & 18/03/2016 & 11.24 & 13 & Pinus pinea & MIX \\
\hline 4677 & 18/03/2016 & 2.06 & 65 & Pinus pinea & 1Bo \\
\hline 4699 & 06/04/2016 & 5.87 & 13 & Pinus pinea & MIX \\
\hline
\end{tabular}

neighbouring strain 2352 (about $5 \mathrm{~m}$ far) (Figs. 1 and 2). Only two ascomata (4601 and 4633) had female genotypes (C-MLG_3 and C-MLG_10) different from those used to inoculate the plants (Table 2). In particular, C-MLG_10 showed a SSR profile, which differs from that of the inoculated strain 2364 (C-MLG_13) for the presence at locus Tb1 of a different allele, which is present in the strains Tb98 and 2292. On the contrary, C-MLG_3 had two loci (Tb151 and Tb46) with alleles not present in any inoculated strain (Supporting Information Table S2). The genotype C-MLG_6 corresponding to the inoculated strain 1Bo was never found as maternal genotype in the truffle ground.

The ascomata found in the plants inoculated with a mixture of strains showed the maternal genotypes C-MLG_8 and C-MLG_14, corresponding to the strains Tb98 and 2352, respectively.

The persistence of the inoculated strains in the areas where the plants were originally planted was also confirmed by mating type analyses of the other 15 ascomata. All these ascomata had the same mating type as the strain used to inoculate the plants where they were collected (Table 2). Nine samples were identified as MAT
1-1-1 and 6 as MAT 1-2-1. In the case of plants inoculated with the mixture of strains, PCRs revealed the presence of both mating types although spatially isolated in different plants: MAT 1-2-1 under the plants 15 and 17 (ascomata 4639 and 4660) and MAT 1-1-1 under the plants 51, 52 (ascomata 4640, 4657 and 4664) and 13 (ascoma 4675) (Fig. 1; Table 2).

A total of 23 root samples taken under 23 of the collected ascomata were processed to characterize mating types of ectomycorrhizas (ECMs) (Fig. 1; Table 2). Molecular analyses with $T$. borchii species-specific primers confirmed the identity of the ECMs morphotyped in each root sample. In total, 115 ECMs identified as $T$. borchii (5 for each collection point) were analysed.

Remarkably, each ECM amplified a single and specific mating type amplicon. All ECMs had the same mating type as the inoculated strain and as the ascoma under which they were collected (Table 2).

Soil analysis also confirmed the persistence of the inoculated mating types. In almost all soil samples, the mating type corresponded to that of the inoculated strain and of the ascoma maternal tissue and ECMs collected 

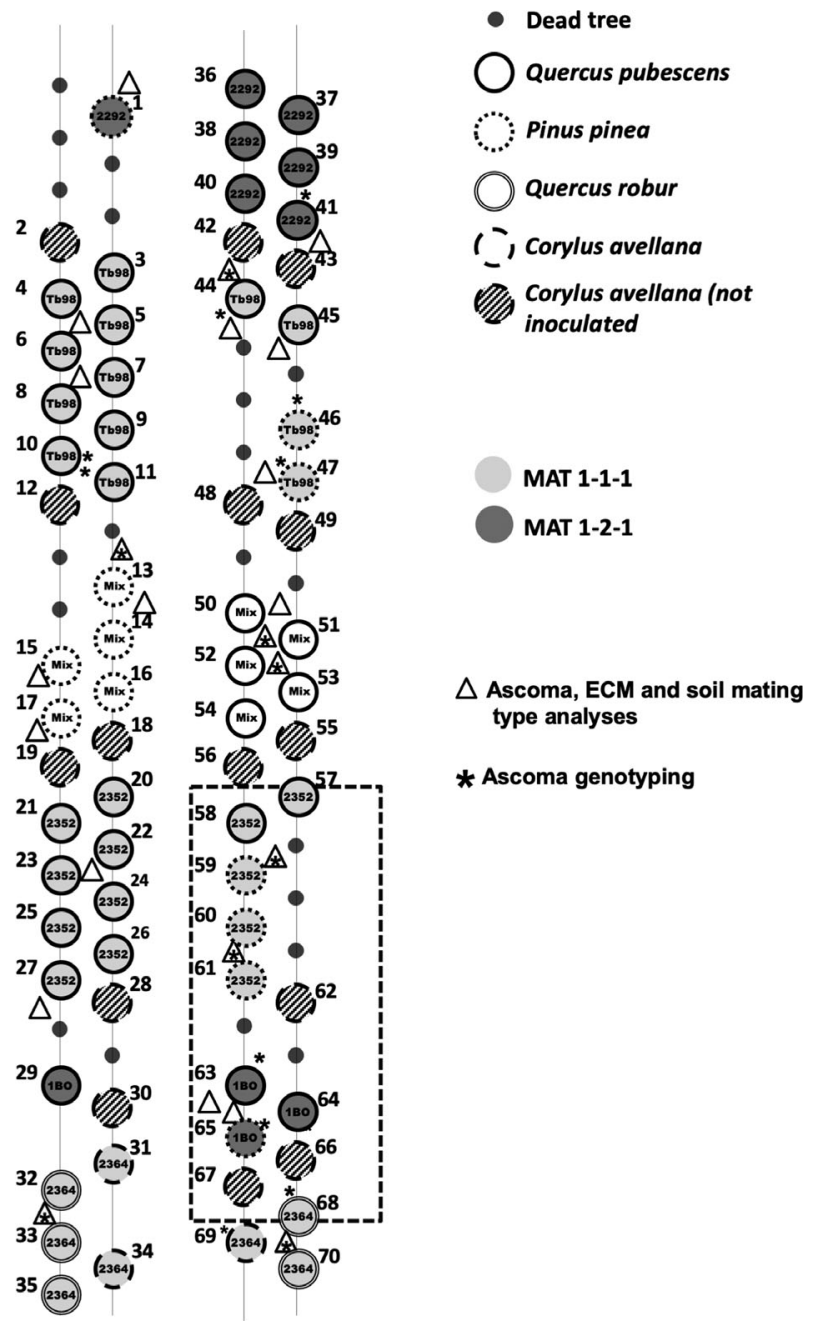

Fig. 1. Scheme of the experimental plantation realized with mycelial inoculated seedlings. The circles show the codes of inoculated strains or their mixture (Mix). Different circle types indicate different host plants. Triangles and asterisks indicate the position of samples and types of analyses applied to them. The dotted rectangle indicates the area of the plantation enlarged in Fig. 2.

in the same position, with only two exceptions: soils collected under ascomata 4677 and 4642 . They were found in the same group of plants where the genotypes of the two ascomata (4601 and 4633) differed from the one used to inoculate the plants (Table 2; Fig. 2).

\section{Genotyping of paternal tissue (spores)}

The SSRs analysis performed on the spores was successful only for 18 of the 33 analysed ascomata. Sixteen paternal genotypes were found on the 18 ascomata characterized by SSRs (Tables 2 and 4). The percentage of success of spore DNA extraction was only $55 \%$ probably due to the difficulties in breaking $T$. borchii spores or the too low quantity of extracted DNA.
MAT 1-1-1

MAT 1-2-1

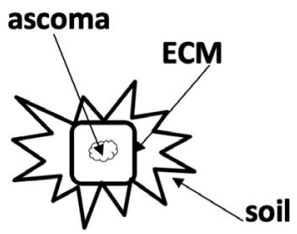

Fig. 2. Area of the plantation where a true hermaphrodite strain was found (C-MLG_14). This strain was found as female in ascomata 4651, 4652 and 4658 and as male in ascoma 4601 located in the adjacent plants. This ascoma presents a new female C-MLG (C-MLG_3).

In zygotes, the $F_{I S}$ was 0.058 with a $p$-value of 0.11 , indicating a non-significant departure from 0 ; consequently, even if the $F_{I S}$ is positive there is no heterozygote deficit.

Most of the paternal C-MLGs were different from the female C-MLGs and were characterized by the recombination of the alleles of the inoculated strains (Fig. 3). Four paternal MLGs (C-MLG_1; C-MLG_2; C-MLG_4, C-MLG 16, ascomata 4600, 4652-4599, 4651 and 4635, respectively) showed new alleles (loci Tb151 and/or Tb46) never detected in the inoculated mycelia, although they were detected in the maternal tissue of ascoma 4601 (Supporting Information Table S1). Two paternal C-MLGs had new alleles not present in any maternal genotype in the loci Tb17 (C-MLG_9) and Tb293 (C-MLG_9 and C-MLG_16) (Fig. 3; Supporting Information Table S2). Only two MLGs (C-MLG_14 and C-MLG_18) were detected as both maternal and paternal genotypes but only one (CMLG_14) according to the P-Sex value can be considered as a true hermaphroditic strain (Table 4 and Supporting Information Table S3). This hermaphroditic C-MLG_14 was found as male and female in adjacent areas of the experimental field 
A

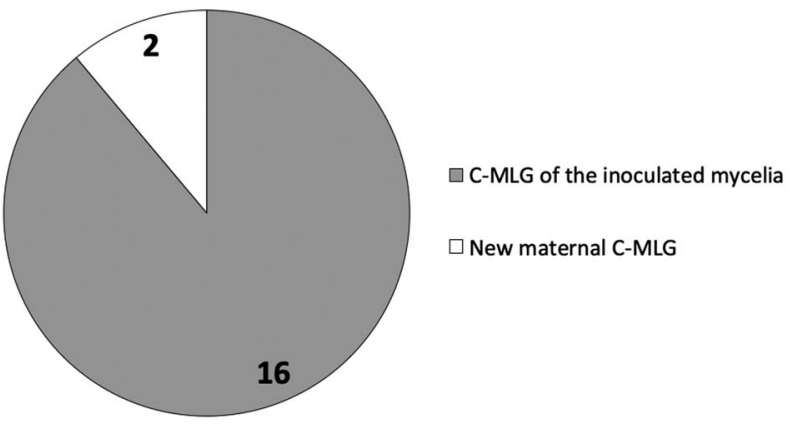

B

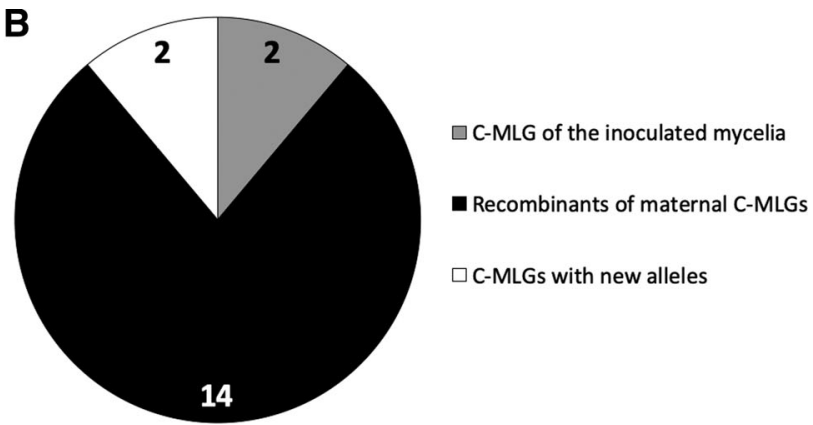

Fig. 3. Characteristics of the maternal (A) and paternal (B) genotypes of the 18 analysed ascomata.

(Fig. 2). Only one C-MLG found only as male (C-MLG_2) for two samples was supported by a significant $P$ sex value, indicating that this genotype is a clone (Supporting Information Table S3).

\section{Discussion}

In this study, truffles harvested in a T. borchii orchard were investigated by using mating type and SSR markers for the first time. Mating type primers were recently designed and tested only on $T$. borchii pure cultures and not applied to environmental samples (Belfiori et al., 2016). On the other hand, SSR analyses were carried out on other truffle species ( $T$. aestivum and $T$. melanosporum) but never on T. borchii (Rubini et al., 2005; Riccioni et al., 2008; Murat et al., 2013; Molinier et al., 2015, 2016; Taschen, et al., 2016; De la Varga et al., 2017; Schneider-Maunory et al., 2018). In this study, T. borchii-specific SSR loci were selected, tested for their polymorphisms on 50 ascomata of different origin and used to assess the genetic structure of $T$. borchii population in the studied truffle orchard. The level of polymorphism of the developed SSR is highly variable

Table 4. Genetic diversity for maternal and paternal genotypes.

Number of sampled ascocarps

Number of inocula genotyped

Maternal genotypes

Number of samples genotyped

Number of genotypes

Number of genotypes with Psex $<0.05$

Maximum number of ascocarps per genotype

Number of genotypes represented by a single ascocarp

Paternal genotypes

Number of genotyped zygotes

Number of homozygous zygotes

Zygotes Fis

Number of genotypes

Number of genotypes with Psex $<0.05$

Maximum number of ascocarps per genotype

Number of male genotypes represented by a single ascocarp

Hermaphrodite genotypes

Total number (number of genotypes whit Psex $<0.05$ )
(He ranges from 0.208 to 0.739 ) as already observed for other Tuber spp. (Murat et al., 2011; Molinier et al., 2013).

Most of the studies on the genetic structure of truffle population have been conducted in human-made or natural truffle grounds where the identity of the strains colonizing roots was not known (Murat et al., 2013; Molinier et al., 2016; Taschen, et al., 2016; De la Varga et al., 2017). On the contrary, the T. borchii plantation under investigation was established with plants inoculated with five different mycelial strains without knowing their mating type. As supposed by lotti et al. (2016), the inoculated strains were found to belong to different mating types, which is the necessary condition for fruiting in a heterotallic fungus like $T$. borchii (Belfiori et al., 2016).

\section{Clonal structure suggests the persistence of the inoculated strains}

Ascoma SSR analysis demonstrated that the maternal CMLGs of the fruiting bodies was the same as the corresponding inoculating strains, as also supported by the significant $P$ sex value of three female genotypes corresponding to the inoculated strains. Several works demonstrated that in Tuber species the maternal tissue of ascomata and surrounding ECMs have the same genotype (Rubini et al., 2011b, Murat et al., 2013; Molinier et al., 2016; Taschen et al. 2016; De la Varga et al., 2017). Moreover, a physical and nutritional link between these fungal structures has been proved (Le Tacon et al., 2013; Deveau et al., 2019). For these reasons, our results suggest the persistence of the inoculated mycelia 9 years after plantation on the root systems. A similar result was already found for seedlings inoculated with the basidiomycete Laccaria bicolor for which the introduced strain was still present in the inoculated plots 10 years after plantation (Selosse et al., 1998).

The maternal genotypes of ascomata 4601 and 4633 (C-MLG_3 and C-MLG_10, respectively) found in adjacent groups of plants at the southern edge of the truffle orchard differed from those of the inoculated mycelia. Ascomata 
4601 had two alleles not present in the inoculated strains (loci Tb151 and Tb46) and this suggests an introgression of a foreign genotype on the host roots inoculated with 1Bo. Ascoma 4633 showed a different combination of the alleles found in the inoculated strains and thus could originate from ECMs colonized by a germinating spore corresponding to an offspring of inoculated mycelia.

Mating type of ECMs and almost all ascomata and soil mycelia was the same as the inoculated strain, confirming the results obtained by SSR analyses. The only exception was found in the group of plants inoculated with the strain 1Bo where a different mating type (MAT 1-1-1) was found in the soil (Fig. 2). Since the strain 2352 located in the adjacent group of plants has MAT 1-1-1, its mycelium was probably able to migrate toward the plants inoculated with strain $1 \mathrm{Bo}$. This migration could also have been favoured by the death of one uninoculated hazel separating the group of plants inoculated with the strains $1 \mathrm{Bo}$ and 2352. Moreover, the strain 1 Bo did probably not establish itself in the truffle ground because of the low level of root colonization at the planting time (data not shown). Indeed 1Bo genotype was not found as maternal genotype in these or other plants and its specific alleles of the loci Tb155 and Tb46 were also never found in any paternal genotype. The 1Bo mycelium was, in fact, isolated in 1997 and repeated subcultures are known to affect the viability and infectivity of a Tuber strain (Piattoni et al., 2017). Both the adjacent strain 2352 and the foreign genotype C-MLG_3 found as female in the ascomata 4658 and 4601 , respectively, could have taken advantage of the scarce colonization of strain 1Bo (Fig. 2). However, we cannot exclude the possibility that the mycelium and ECMs of strain 1Bo were still present in the soil and the production of the ascoma of this strain could have occurred.

The plants inoculated with the mixture of strains showed that MAT 1-1-1 and MAT 1-2-1 dominated in separate areas either considering ECMs, soil mycelium or maternal tissue of ascomata. In order to better understand the dynamics of the mating types, we analysed another 29 ascomata, and the respective ECMs and soils collected in the following year (February-March 2017). These additional analyses confirmed that, the ascomata, mycorrhizas and soil mycelium had the same mating type of the inoculated strain (Supporting Information Table S5 and Fig. S5). As in 2016, the only exceptions were the two sample sets collected under plants inoculated with the strain 1Bo. Fourteen of these 29 ascomata were collected under the plants inoculated with the mixture of strains and only MAT 1-1-1 was found in these new samples (Supporting Information Table S5 and Fig. S5). This result confirms that also in $T$. borchii a single mating type tends to dominate in a single soil patch, as found for T. melanosporum and $T$. aestivum in natural and cultivated truffle ground, and confirms that in field conditions only one strain or multiple strains of the same mating type tend to colonize one single plant (Rubini et al., 2011b; Linde and Selmes,
2012; Zampieri et al., 2012; Murat et al., 2013; Rubini et al., 2014; Molinier et al., 2016; De la Varga et al., 2017). This can be explained by considering that a vegetative incompatibility (VI) system exists in T. borchii, which prevents hyphal interactions between hyphae of different strains (Sbrana et al., 2007). Although the sets of genes which regulated VI in filamentous ascomycetes was not found in $T$. melanosporum genome (lotti et al., 2012b), other molecular mechanisms controlling self/nonself recognition are involved in segregation between strains of different mating types in the field (Rubini et al., 2011b; Selosse et al., 2013) and prevent hyphal fusion in axenic conditions (lotti et al., 2012b).

\section{Meiospores are the most important origin of male genotype}

Most of the male C-MLGs are new genotypes and seem to be originated from spores, confirming the hypothesis made for $T$. melanosporum that the locally dispersed spores are the major source of male genotypes (Selosse et al., 2013; Le Tacon et al., 2016; Taschen et al., 2016; De la Varga et al., 2017). In fact, the male C-MLGs showed an allele recombination of the alleles present in the maternal genotypes, which are mostly ( 5 out of 6 ) represented by the inoculated strains. The numbers of generations to account for the observed diversity of paternal recombinant genotypes should be at least two. In fact, for example, C-MLG 15 could derive from a first mating between C-MLG_8 and CMLG_18 and then the mycelium/conidia originated from the spores of the formed ascoma could have fertilized strain 2352 or 2364 . Thus the ascoma production started before our first survey with trained dogs in the truffle ground (lotti et al., 2016). Only three male genotypes presented new alleles and perhaps we could suppose that they originated from spores coming from other sites. Although it is not possible to exclude the arrival of spores from the natural $T$. borchii grounds, which are located several kilometres away (lotti et al., 2016), likely they could also have come from cultivated $T$. borchii orchards in the area. Tuber borchii cultivation has become very popular in Italy in the last few years after the first results obtained by spore inoculation (Zambonelli et al., 2000).

The role of spores in fertilization could explain the increase in truffle production obtained by inoculating spores in the field (Murat et al., 2016) and the decrease in production attributed to ascoma overharvesting in natural truffle grounds. Moreover, it stresses the importance of animals in spore dispersal (Piattoni et al., 2014; Zambonelli et al., 2017; Ori et al., 2018) not only to promote truffle colonization of new areas but also to favour truffle fertilization in non-productive plants.

Only one strain (strain 2352; MAT 1-1-1; C-MLG_14) displayed actual evidence for hermaphroditism. This strain was found as male in one ascoma (4601) collected in the adjacent plants inoculated with another strain (1Bo, MAT 1-2-1). 
This ascoma was located under the same group of plants where both mating types were found in the soil, and the CMLG_14 was also found as female in one ascoma (4658). Although not statistically supported, another C-MLG (CMLG_18) was found in adjacent groups of plants as male and female, supporting the possibility that fertilization can occur also between mycelia. These results suggest that hermaphroditism is not frequent in $T$. borchii, as already reported for T. melanosporum (De la Varga et al., 2017).

\section{Consideration on the truffle life cycle}

Although this study gives new important insights into truffle biology, it was not able to completely resolve the mystery of the reproduction strategy in truffles. How are the ascospores able to fertilize the mycelium of different mating types? We can suppose that the ascospores germinate and originate a mycelium that, directly or by conidia formation, fertilizes other compatible mycelia in the soil or on the roots. As suggested for T. melanosporum, competition and/or vegetative incompatibility events can prevent the growth of this new mycelium in the root system extensively colonized with the mycelium of the opposite mating type (De la Varga et al., 2017). However, when host roots are not colonized by other truffle strains, the new genotype could be able to establish on them and function as a new female (maternal) genotype. T. melanosporum and T. magnatum presented a significant heterozygote deficit with high levels of inbreeding (Paolocci et al., 2006; Riccioni et al., 2008; Taschen et al. 2016; De la Varga et al., 2017). In T. borchii, we did not find such inbreeding since Fis was not significantly different from 0 , suggesting no departure from panmixia in the Cadriano population. This means that all opposite genotypes have the same probability to breed. Could it be explained by the possibility of $T$. borchii to form conidia? Indeed, the conidia formation in T. melanosporum and T. magnatum was never observed in contrast to $T$. borchii and other species in the Puberulum clade (Urban et al., 2004; Healy et al., 2012; Ian Hall personal communication). Additional studies will be necessary to clarify these aspects of truffle life cycle, focusing on field experiments to detect conidia in the Cadriano population as well as in the laboratory to induce conidia production and ascospore germination.

\section{Experimental procedures}

\section{Plantation and ascoma sampling}

The study was carried out in an experimental truffle orchard in Cadriano (Bologna, Italy) established in autumn 2007-2008, planting seedlings of Pinus pinea L., Quercus pubescens Willd., Quercus robur L. and Corylus avellana L. The seedlings were inoculated with five different $T$. borchii pure cultures (strains Tb98, 2352, 2292, 1Bo, 2364) separately and together as described by lotti et al. (2016). Seedlings inoculated with the same strain(s) were grouped along four rows and separated by non-inoculated guard plants of $C$. avellana (Fig. 1). Ascoma production was firstly verified in 2016 when 99 ascomata (total weight $722.2 \mathrm{~g}$ ) were collected through February and March (lotti et al., 2016). Each ascoma was weighed and fragments were either freeze-dried at $-65^{\circ} \mathrm{C}$ for three days in a Virtis Benchtop $2 \mathrm{~K}$ lyophilizer (SP Industries) and then stored at $-20^{\circ} \mathrm{C}$ (gleba) or fixed in FAA (gleba and peridium) for molecular and morphological analyses, respectively. The remaining portion of each ascoma was dried and deposited in the Mycological Herbarium of Hypogeous Fungi of the Bologna University (CMI-UNIBO). Fruiting position and metadata of 33 truffles processed in this study are reported in Fig. 1 and Table 3.

\section{Mycelial strains}

The five strains of $T$. borchii used for the seedling inoculation were preserved at $4{ }^{\circ} \mathrm{C}$ in $15 \mathrm{ml}$ tubes containing $6 \mathrm{ml}$ of Potato Dextrose Agar half strength (hsPDA) (Difco) in the culture collection of the Mycological Center of Bologna University (CMI-UNIBO). The cultures were renewed every year on fresh hsPDA.

For their genetic characterization, the cultures were transferred on fresh modified woody plant medium (mWPM) (lotti et al., 2005) without agar addition and incubated in the dark at $23 \pm 1^{\circ} \mathrm{C}$ for 60 days.

\section{Soil and root sampling}

Soil and ECMs were sampled under 23 ascomata collected in February 2016 (Table 2) during truffle surveys. A 20-cm-long soil core was taken under each ascoma by using a 6-cm-diameter soil corer. ECMs were carefully separated from soil and washed in sterile water, while any root fragment, stone, or organic debris was removed under a stereomicroscope $(\times 12)$ from the remaining soil.

ECMs were examined under a stereomicroscope $(\times 40)$ and those of $T$. borchii were identified based on their morphological features (Zambonelli et al., 1993). Tuber borchii ECMs were vortexed in a $1.5 \mathrm{ml}$ tube for $30 \mathrm{~s}$, spun for $2 \mathrm{~min}$ at $17,000 \mathrm{~g}$ to remove soil particles from the mantle and then stored in sterile water at $-80^{\circ} \mathrm{C}$ pending further molecular characterization.

Soil samples were freeze-dried at $-65^{\circ} \mathrm{C}$ for three days and then pulverized and homogenized by mortar and pestle. Three $15 \mathrm{ml}$ tubes containing $5 \mathrm{~g}$ of soil were prepared for each sample and then stored at $-20^{\circ} \mathrm{C}$ until DNA extraction.

\section{Molecular assays}

DNA extraction. The complexity of the genetic analyses carried out in this study and, in particular, the necessity 
to differentially target the maternal and paternal tissues of ascomata have implicated the selection of different strategies to isolate and/or amplify DNAs.

A direct PCR strategy avoiding DNA isolation (lotti and Zambonelli, 2006) was applied to confirm the identity of ECMs and to characterize the mating type of mycelia, ascomata and ECMs.

Soil DNA was extracted using the CTAB-based protocol described by lotti et al. (2012c) adapted for $1 \mathrm{~g}$ of soil. Crude DNA solutions were then purified using the Nucleospin Plant II kit (Macherey-Nagel, Düren, Germany) following the manufacturer's instructions. Total DNAs were quantified by a NanoDrop ND-1000 Spectrophotometer (Thermo Scientific) and their quality evaluated with optical density (OD) 260/280 $\mathrm{nm}$ and 260/230.

DNA extraction for analyses of SSR polymorphisms was performed using three different protocols: (i) DNeasy ${ }^{\circledR}$ Plant Mini Kit (Qiagen, Hilden, Germany) was used to isolate DNA from $50 \mathrm{mg}$ of lyophilized mycelia by applying the manufacturer's instructions; (ii) Nucleospin Plant II kit (MachereyNagel, Düren, Germany) was used to isolate DNA from $50 \mathrm{mg}$ of frozen gleba (corresponding to the female tissue) by applying the manufacturer's instructions; (iii) spore DNA was isolated by placing thin slices of lyophilized gleba in $1 \mathrm{ml}$ of sterile water within a petri plate; after precipitation from the floating gleba slice to the bottom of the plate, about 200 spores were transferred in a $1.5 \mathrm{ml}$ tube and their DNA isolated according to De la Varga et al. (2017). DNA extraction from each spore sample was repeated up to three times if the amplification of paternal genotypes failed.

DNA extracts were stored at $-20^{\circ} \mathrm{C}$ until processed.

Tuber borchii identification. The species-specific primer pair Tbol-Tboll (Amicucci et al., 1998) were used to confirm the identity of the morphotyped $T$. borchii ECMs by direct PCR and to detect the presence of $T$. borchii extraradical mycelium in DNA soil extracts. For PCRs, we used $1 \mu$ of a 1:10 dilution of DNA (10-50 ng DNA) in a reaction volume of $10 \mu$ l. The REDTaq DNA polymerase and REDTaq PCR reaction buffer $(1.1 \mathrm{mM} \mathrm{MgCl} 2$ final concentration) were used according to the protocol of SIGMA, with $200 \mu \mathrm{M}$ of each dNTP, $0.2 \mu \mathrm{M}$ of each primer and $75 \mu \mathrm{g}$ BSA (only for ECMs). PCR reactions were performed in a BioRad thermalcycler with the following conditions: $6 \mathrm{~min}$ at $94^{\circ} \mathrm{C}$ followed by 34 cycles of denaturation at $94^{\circ} \mathrm{C}$ for $30 \mathrm{~s}$, annealing at $50^{\circ} \mathrm{C}$ for $30 \mathrm{~s}$, extension at $72^{\circ} \mathrm{C}$ for $30 \mathrm{~s}$ and a final extension at $72{ }^{\circ} \mathrm{C}$ for $5 \mathrm{~min}$. PCR products were run on $2 \%$ agarose gel and visualized by staining with ethidium bromide.

Mating type identification. Mating type identification of pure cultures, ascomata, ECMs (five from each soil sample) and extraradical soil mycelium was performed by applying a multiplex PCR, using both the specific primer pairs B1-B3 and B23-B33 (Belfiori et al., 2016) designed to identify the T. borchii MAT 1-1-1 and MAT 1-2-1 genes, respectively.

Multiplex PCRs of mating type genes were performed in a total volume of $25 \mu \mathrm{l}$ consisting of $1 \times$ Ex-Taq Buffer (TaKaRa), $400 \mathrm{nM}$ for each dNTP, $40 \mu \mathrm{g}$ of bovine serum albumin, $400 \mathrm{nM}$ for each primer and $0.75 \mathrm{U}$ of $\mathrm{Ex} \mathrm{Taq}^{\circledR}$ DNA polymerase (TaKaRa). Few aerial hyphae, or small portions of gleba (sterile veins) and ECM mantle were transferred directly to the PCR tubes in place of the extracted DNA. The direct PCRs were performed with the following conditions: $6 \mathrm{~min}$ at $94^{\circ} \mathrm{C}$ followed by 34 cycles of denaturation at $94^{\circ} \mathrm{C}$ for $30 \mathrm{~s}$, annealing at $60^{\circ} \mathrm{C}$ for $30 \mathrm{~s}$, extension at $72^{\circ} \mathrm{C}$ for $30 \mathrm{~s}$, and a final extension at $72{ }^{\circ} \mathrm{C}$ for $5 \mathrm{~min}$. PCR products were run on $2 \%$ agarose gel. The same conditions were applied to identify the mating type of extraradical soil mycelium by adding $30 \mathrm{ng}$ of soil DNA extracts to the PCR mixtures and avoiding BSA addition.

Selection of polymorphic SSR primers. MISA program (http://pgrc.lpkgatersleben.de/misa/download/misa.pl) was used to search for SSR markers in the recently released T. borchii genome (Murat et al., 2018). Tri-, tetra-, pentaand hexanucleotide satellites with at least six repetitions and excluding composite SSRs were selected as search parameter. Subsequently, primer pairs were designed based on the sequences flanking the selected SSRs using Primer 3 software (Rozen and Skaletsky, 2000). The functionality of the designed primers was tested using AmplifX software (http://crn2m.univ-mrs.fr/pub/amplifx-dist). After in silico analyses, a total of 31 primer pairs were designed and tested in PCR and visualized in $4 \%$ agarose gel. Among then 14 were retained since they produced only one band per sample and showed polymorphisms. They were used to search for polymorphisms on 50 ascomata from Italy and Hungary (Supporting Information Tables S1 and S4). The genotyping was realized in the Gentyane platform (INRA, Clermont-Ferrand, France). The mating type of these ascomata was also determined as described above.

SSR identification. The extracted DNA from mycelia, gleba and spores was amplified using a set of primer pairs amplifying the 14 polymorphic SSR loci (Table 1 and Supporting Information Table S4). The amplification of maternal genotypes (gleba) was carried out only for the ascomata on which the amplification of paternal genotypes (spores) was successful.

PCRs were performed in a total volume of $10 \mu \mathrm{l}$ consisting of $1 \times$ REDTaq Buffer (1.1 mM MgCl 2 final concentration), $200 \mu \mathrm{M}$ for each dNTP, $0.2 \mu \mathrm{M}$ of each primer and $1 \mathrm{U}$ DNA polymerase (RED Taq Sigma-Aldrich) and $1 \mu \mathrm{l}$ template DNA diluted 10 times (10-50 ng DNA).

The PCR reactions were performed with the following conditions: $4 \mathrm{~min}$ at $94^{\circ} \mathrm{C}$ followed by 34 cycles of 
denaturation at $94^{\circ} \mathrm{C}$ for $30 \mathrm{~s}$, annealing at $55-60-65^{\circ} \mathrm{C}$ for $30 \mathrm{~s}$ depending on the primer, extension at $72^{\circ} \mathrm{C}$ for 30 s, and a final extension at $72^{\circ} \mathrm{C}$ for $5 \mathrm{~min}$. PCR products were run on $4 \%$ agarose gel.

Genomic DNA was analysed using an ABI 3730XL sequencer (Applied Biosystems, Foster City, CA) from 'Plateforme de Génotypage GENTYANE' (Clermont-Ferrand, France). The size of the alleles was analysed with the Peak scanner software v.1.0.

SSR analyses were carried out only on ascomata because, when the genome sequencing of $T$. borchii (Murat et al., 2018) made possible to select the SSR markers, the mycorrhizas were already analysed for mating type characterization by using direct PCR and successively disrupted (see above).

\section{Data analyses}

Gene diversity or expected heterozygosity $(\mathrm{He})$ was calculated using GenAlex v6.51.b2 (Peakall and Smouse, 2006) in Excel 2011. The He is a measure of the probability that two copies of the same gene chosen randomly in a population will have different alleles (Nei, 1973). This estimator is based on the allele frequency and can be calculated as $\mathrm{He}=1 \sum \mathrm{Rpi}^{2}$. The genotypic diversity was calculated using Multilocus 1.3 (Agapow and Burt, 2001). It corresponds to the probability that two individuals taken at random have different genotypes. In other words, this value is 0 if every individual has the same genotype, and 1 if every individual has a different genotype.

The fixation index $F_{I S}$ was calculated for zygote (maternal + paternal genotypes) in the Cadriano population using GenAlex v6.51.b2. In this analysis, only the nine polymorphic SSR in this population were used. The significant departure from $F_{I S}=0$ was estimated using the $R$ script developed by Taschen et al. (2016); script available at https://doi.org/10.5061/dryad.vm11r.

MLG analysis of the inoculated mycelia, and the maternal (gleba) and paternal (spores) ascoma tissues harvested in Cadriano was realized using the 14 polymorphic SSR markers combined with the mating type gene. MLGsim 2.0 (Stenberg et al., 2003) was used for MLG identification and the calculation of the likelihood (PSex) that copies of MLGs result from sexual reproduction or clonal spread. The threshold value $(<0.05)$ for testing the significance of the PSex for each genotype was estimated using 1000 simulations. When the PSex values fell below the threshold value, it was concluded that identical genotypes originated from clonal multiplication.

\section{Acknowledgements}

UMR 1136 is financed by the French National Research Agency (ANR) as part of the 'Investissements d'Avenir' program
(ANR-11-LABX-0002-01, Lab of Excellence ARBRE) and CM benefits of the project CulturTruf financed by FranceAgriMer (CASDAR). We are grateful to Dr Fabien Halkett for population genetic critical discussions. We also thank to Susan West for her professional revision of the English.

\section{References}

Agapow, P.M., and Burt, A. (2001) Indices of multilocus linkage disequilibrium. Mol Ecol Notes 1: 101-102.

Amicucci, A., Zambonelli, A., Giomaro, G., Potenza, L., and Stocchi, V. (1998) Identification of ectomycorrhizal fungi of the genus Tuber by species-specific ITS primers. Mol Ecol 7: 273-277.

Belfiori, B., Riccioni, C., Paolocci, F., and Rubini, A. (2016) Characterization of the reproductive mode and life cycle of the whitish truffle Tuber borchii. Mycorrhiza 26: 515-527.

Bonito, G.M., Gryganskyi, A.P., Trappe, J.M., and Vilgalys, R. (2010) A global meta-analysis of Tuber ITS rDNA sequences: species diversity, host associations and long-distance dispersal. Mol Ecol 19: 4994-5008.

Chevalier, G. (1973) Synthese axenique des mycorhizes de Tuber brumale Vitt. a partir de cultures puresdu champignon. Ann Phytopathol 5: 163-182.

Chevalier, G., and Grente, J. (1978) Application practique de la symbiose ectomycorrhizienne: production a grande echelle de plants mycorrhizes par la truffe (Tuber melanosporum Vitt.). Mushroom Sci 10: 483-505.

De la Varga, H., Le Tacon, F., Lagoguet, M., Todesco, F., Varga, T., Miquel, I., et al. (2017) Five years investigation of female and male genotypes in Périgord black truffle (Tuber melanosporum Vittad.) revealed contrasted reproduction strategies. Environ Microbiol 19: 2604-2615.

Deveau, A., Clowez, P., Petit, F., Maurice, J.-P., Todesco, F., Murat, C., et al. (2019) New insights into black truffle biology: discovery of the potential connecting structure between a Tuber aestivum ascocarp and its host root. Mycorrhiza 29: 219-226.

Gardin, L. (2005). I tartufi minori in Toscana. Gli ambienti di crescita dei tartufi marzuolo e scorzone. Firenze: Quaderno ARSIA [WWW document]. URL http://www. provincia.pisa.it/uploads/2012_08_28_17_46_12.pdf

Giomaro, G., Sisti, D., and Zambonelli, A. (2005) Cultivation of edible ectomycorrhizal fungi by in vitro mycorrhizal synthesis. In In Vitro Culture of Mycorrhizas, Vol. 4, Declerck, S., Strullu, D.G., and Fortin, J.A. (eds). Berlin, Heidelberg: Springer-Verlag, pp. 253-267.Soil Biology Series

Hall, I., Brown, G., and Zambonelli, A. (2007) Taming the Truffle. The History, Lore, and Science of the Ultimate Mushroom. Portland, OR: Timber Press.

Hall, I., Fitzpatrick, N., Miros, P., and Zambonelli, A. (2017) Counter-season cultivation of truffles in the southern hemisphere: an update. Ital J Mycol 46: 21-36.

Healy, R.A., Smith, M.E., Bonito, G.M., Pfister, D.H., Ge, Z. W., Guevara, G.G., et al. (2012) High diversity and widespread occurrence of mitotic spore mats in ectomycorrhizal Pezizales. Mol Ecol 22: 1717-1732.

lotti, M., and Zambonelli, A. (2006) A quick and precise technique for identifying ectomycorrhizas by PCR. Mycol Res 110: $60-65$. 
lotti, M., Amicucci, A., Stocchi, V., and Zambonelli, A. (2002) Morphological and molecular characterization of mycelia of some Tuber species in pure culture. New Phytol 155: 499-505.

lotti, M., Barbieri, E., Stocchi, V., and Zambonelli, A. (2005) Morphological and molecular characterization of mycelia of ectomycorrhizal fungi in pure culture. Fungal Divers 19: 51-68.

Iotti, M., Piattoni, F., and Zambonelli, A. (2012a) Techniques for host plant inoculation with truffles and other edible ectomycorrhizal mushrooms. In Edible Ectomycorrhizal Mushrooms, Current Knowledge and Future Prospects, Vol. 34, Zambonelli, A., and Bonito, G.M. (eds). Berlin, Heidelberg: Springer-Verlag, pp. 145-161. Soil Biology Series

lotti, M., Rubini, A., Tisserant, E., Kholer, A., Paolocci, F., and Zambonelli, A. (2012b) Self/nonself recognition in Tuber melanosporum is not mediated by a heterokaryon incompatibility system. Fungal Biol 116: 261-275.

lotti, M., Leonardi, M., Oddis, M., Salerni, E., Baraldi, E., and Zambonelli, A. (2012c) Development and validation of a real-time PCR assay for detection and quantification of Tuber magnatum in soil. BMC Microbiol 12: 93.

Iotti, M., Piattoni, F., Leonardi, P., Hall, I.R., and Zambonelli, A. (2016) First evidence for truffle production from plants inoculated with mycelial pure cultures. Mycorrhiza 26: 793-798.

Lancellotti, E., lotti, M., Zambonelli, A., and Franceschini, A. (2016) The Puberulum group sensul lato (whitish truffles). In True Truffle (Tuber Spp.) in the World, Vol. 47, Zambonelli, A., Murat, C., and lotti, M. (eds). Berlin, Heidelberg: Springer-Verlag, pp. 105-124. Soil Biology Series

Le Tacon, F., Zeller, B., Plain, C., Hossann, C., Bréchet, C., and Robin, C. (2013) Carbon transfer from the host to Tuber melanosporum mycorrhizas and ascocarps followed using a $13 \mathrm{C}$ pulse-labeling technique. PLoS One 8: e64626.

Le Tacon, F., Rubini, A., Murat, C., Riccioni, C., Robin, C., Belfiori, B., et al. (2016) Certainties and uncertainties about the life cycle of the Périgord black truffle (Tuber melanosporum Vittad.). Ann For Sci 73: 105-117.

Linde, C.C., and Selmes, H. (2012) Genetic diversity and mating type distribution of Tuber melanosporum and their significance to truffle cultivation in artificially planted truffieres in Australia. Appl Environ Microbiol 78: 6534-6539.

Martin, F., Kohler, A., Murat, C., Balestrini, R., Coutinho, P. M., Jaillon, O., et al. (2010) Périgord black truffle genome uncovers evolutionary origins and mechanisms of symbiosis. Nature 464: 1033-1038.

Molinier, V., Murat, C., Morin, E., Gollotte, A., Wipf, D., and Martin, F. (2013) First identification of polymorphic microsatellite markers in the burgundy truffle, Tuber aestivum (Tuberaceae). Appl Plant Sci 1: 1200220.

Molinier, V., Murat, C., Peter, M., Gollotte, A., De la Varga, H., Meier, B., et al. (2015) SSR-based identification of genetic groups within European populations of Tuber aestivum Vittad. Mycorrhiza 26: 99-110.

Molinier, V., Murat, C., Baltensweiler, A., Büntgen, U., Martin, F., Meier, B., et al. (2016) Fine-scale genetic structure of natural Tuber aestivum sites in southern Germany. Mycorrhiza 26: 895-907.
Morara, M., Saitta, A., Venturella, G., Gargano, M.L., and Zambonelli, A. (2009) I funghi ipogei dell'Emilia Romagna e della Sicilia a confronto. In Annales Confederationis Europaeae Mycologiae Mediterraneensis, Vol. 2009, Venturella, G., and Gargano, M.L. (eds). Italia, Europe: Cefalù, pp. 53-68.XVII Giornate Micologiche della CEMM, 14-21 Novembre

Murat, C., Riccioni, C., Belfiori, B., Cichocki, N., Labbé, J., Morin, E., et al. (2011) Mining microsatellites in the Perigord black truffle genome and identification of new molecular markers. Fungal Genet Biol 48: 592-601.

Murat, C., Rubini, A., Riccioni, C., De la Varga, H., Akroume, E., Belfiori, B., et al. (2013) Fine-scale spatial genetic structure of the black truffle (Tuber melanosporum) investigated with neutral microsatellites and functional mating type genes. New Phytol 199: 176-187.

Murat, C., Bonneau, L., De la Varga, H., Olivier, J.M., Sandrine, F., and Le Tacon, F. (2016) Trapping truffle production in holes: a promising technique for improving production and unravelling truffle life cycle. Ital J Mycol 45: 47-53.

Murat, C., Kuo, A., Barry, W.W., Clum, A., Dockter, R.B., Fauchery, L., et al. (2018) Draft genome sequence of Tuber borchii Vittad., a whitish edible truffle. Genome Announc 6: e00537-e00518.

Nei, M. (1973) Analysis of gene diversity in subdivided populations. PNAS 70: 3321-3323.

Ori, F., Trappe, J., Leonardi, M., Iotti, M., and Pacioni, G. (2018) Crested purcopines (Hystrix cristata): mycophagist spore disperser of the ectomycorrhizal truffle Tuber aestivum. Mycorrhiza 28: 561-565.

Palenzona, M., Chevalier, G., and Fontana, A. (1972) Sintesi micorrizica tra i miceli in coltura pura di Tuber brumale, T. melanosporum, T. rufum e semenzali di conifere e latifoglie. Allionia 18: 41-52.

Paolocci, F., Rubini, A., Riccioni, C., and Arcioni, S. (2006) Reevaluation of the life cycle of Tuber magnatum. Appl Environ Microbiol 72: 2390-2393.

Peakall, R., and Smouse, P.E. (2006) GenAlEx 6: genetic analysis in excel. Population genetic software for teaching and research. Mol Ecol Notes 6: 288-295.

Piattoni, F., Amicucci, A., lotti, M., Ori, F., Stocchi, V., and Zambonelli, A. (2014) Viability and morphology of Tuber aestivum spores after passage through the gut of Sus scrofa. Fungal Ecol 9: 52-60.

Piattoni, F., Leonardi, P., Boutahir, S., Iotti, M., and Zambonelli, A. (2017) Viability and infectivity of Tuber borchii after cryopreservation. CryoLetters 38: 58-64.

Riccioni, C., Belfiori, B., Rubini, A., Passeri, V., Arcioni, S., and Paolocci, F. (2008) Tuber melanosporum outcrosses: analysis of the genetic diversity within and among its natural populations under this new scenario. New Phytol 180: 466-478.

Rozen, S., and Skaletsky, H. (2000) Primer3 on the WWW for general users and for biologist programmers. In Bioinformatics Methods and Protocols, Vol. 132, Misener, S., and Krawetz, S.A. (eds). Totowa, NJ: Humana Press, pp. 365-386. Methods in Molecular Biology ${ }^{\mathrm{TM}}$

Rubini, A., Paolocci, F., Riccioni, C., Vendramin, G.G., and Arcioni, S. (2005) Genetic and phylogeographic structures of the symbiotic fungus Tuber magnatum. Appl Environ Microbiol 71: 6584-6589.

Rubini, A., Belfiori, B., Riccioni, C., Tisserant, E., Arcioni, S., Martin, F., and Paolocci, F. (2011a) Isolation and 
characterization of MAT genes in the symbiotic ascomycete Tuber melanosporum. New Phytol 189: 710-722.

Rubini, A., Belfiori, B., Riccioni, C., Arcioni, S., Martin, F., and Paolocci, F. (2011b) Tuber melanosporum: mating type distribution in a natural plantation and dynamics of strains of different mating types on the roots of nurseryinoculated host plants. New Phytol 189: 723-735.

Rubini, A., Riccioni, C., Belfiori, B., and Paolocci, F. (2014) Impact of the competition between mating types on the cultivation of Tuber melanosporum: Romeo and Juliet and the matter of space and time. Mycorrhiza 24: 19-27.

Sbrana, C., Nuti, M.P., and Giovanetti, M. (2007) Selfanastomosing ability and vegetative incompatibility of Tuber borchii isolates. Mycorrhiza 17: 667-675.

Schneider-Maunoury, L., Clément, C., Coves, H., Lambourdière, J., Leclercq, S., Richard, F., et al. (2018) Is Tuber melanosporum colonizing the roots of herbaceous, non-ectomycorrhizal plants? Fungal Ecol 31: 59-68.

Selosse, M.A., Jacquot, D., Bouchard, D., Martin, F., and Le Tacon, F. (1998) Temporal persistence and spatial distribution of an American inoculant strain of the ectomycorrhizal basidiomycete Laccaria bicolor in a French forest plantation. Mol Ecol 7: 561-573.

Selosse, M.A., Taschen, E., and Giraud, T. (2013) Do black truffles avoid sexual harassment by linking mating type and vegetative incompatibility? New Phytol 199: 10-13.

Selosse, M.A., Schneider-Maunoury, L., Taschen, E., Rousset, F., and Richard, F. (2017) Black truffle, a hermaphrodite with forced unisexual behavior. Trends Microbiol 25: 784-787.

Stenberg, P., Lundmark, M., and Saura, A. (2003) MLGsim: a program for detecting clones using a simulation approach. Mol Ecol Notes 3: 329-331.

Taschen, E., Rousset, F., Sauve, M., Benoit, L., Dubois, M., Richard, F., and Selosse, M. (2016) How the truffle got its mate: insights from genetic structure in spontaneous and planted Mediterranean populations of Tuber melanosporum. Mol Ecol 25: 5611-5627.

Urban, A., Neuner-Plattner, I., Krisai-Greilhuber, I., and Haselwandter, K. (2004) Molecular studies on terricolous microfungi reveal novel anamorphs of two Tuber species. Mycol Res 108: 749-758.

Zambonelli, A., and Morara, M. (1984) Le specie di Tuberales dell'Emilia Romagna, ecologia e distribuzione. Natura e Montagna 4: 9-32.

Zambonelli, A., Salomoni, S., and Pisi, A. (1993) Caratterizzazione anatomo-morfologica e micromorfologica delle micorrize di Tuber spp. su Quercus pubescens Willd. Micol Ital 3: 73-90.

Zambonelli, A., lotti, M., Rossi, I., and Hall, I. (2000) Interaction between Tuber borchii and other ectomycorrhizal fungi in a field plantation. Mycol Res 104: 698-702.
Zambonelli, A., lotti, M., Giomaro, G., Hall, I., and Stocchi, V. (2002) T. borchii cultivation: an interesting perspective. In Edible Mycorrhizal Mushrooms. Proceedings of 2nd International Workshop on Edible Ectomycorrhizal Mushrooms, Hall, I., Wang, Y., Danell, E., and Zambonelli, A. (eds). Christchurch, New Zealand: New Zealand Institute for Crop and Food Research, CD ROM.

Zambonelli, A., lotti, M., and Piattoni, F. (2008) Problems and perspectives in the production of Tuber infected plants. In Mushroom Biology and Mushroom Products. Proceeding of the Sixth International Conference on Mushroom Biology and Mushroom Products, Lelley, J.I., and Buswell, J.A. (eds). Krefeld, Germany: GAMU GmbH, pp. 263-271.

Zambonelli, A., lotti, M., and Hall, I. (2015) Current status of truffle cultivation: recent results and future perspectives. Ital J Mycol 44: 31-40.

Zambonelli, A., Murat, C., and lotti, M. (2016) True truffle (Tuber spp.) in the world. In Soil Biology, Vol. 47. Berlin, Heidelberg: Springer-Verlag.

Zambonelli, A., Ori, F., and Hall, I. (2017) Mycophagy and spore dispersal by vertebrates. In The Fungal Community. Its Organization and Role in Ecosystems, 4th ed, Dighton, J., and White, J.F. (eds). Boca Raton, FL: CRC Press Taylor and Francis Group, pp. 347-358.

Zampieri, E., Rizzello, R., Bonfante, P., and Mello, A. (2012) The detection of mating type genes of Tuber melanosporum in productive and non productive soils. Appl Soil Ecol 57: 9-15.

\section{Supporting Information}

Additional Supporting Information may be found in the online version of this article at the publisher's web-site:

Table S1 Multilocus genotypes (MLG) found in the 50 ascomata analysed from different populations.

Table S2 Multilocus genotypes (C-MLG) found in the Cadriano plantation.

Table S3 Genotype description, probability of genotype occurrence resulting from distinct sexual events (PSex) for all samples harvested in the plantations.

Table S4 Tested microsatellite primers. In bold the selected polymorphic microsatellites.

Table and Fig. S5 Mating type analysis of the ascomata, ectomycorrhizas and soil mycelia of the samples collected in 2017. In the figure triangles indicate the position of samples analysed. 